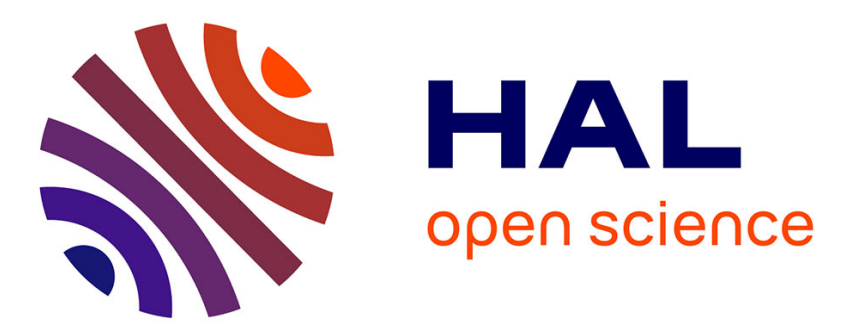

\title{
Combined model of human skin - heat transfer in the vein and tissue: experimental and numerical study
}

Domoina Ratovoson, Vincent Huon, Vincent Costalat, Franck Jourdan

\section{To cite this version:}

Domoina Ratovoson, Vincent Huon, Vincent Costalat, Franck Jourdan. Combined model of human skin - heat transfer in the vein and tissue: experimental and numerical study. Quantitative InfraRed Thermography Journal, 2011, 8 (2), pp.165-186. 10.3166/qirt.8.165-186 . hal-00686621

\section{HAL Id: hal-00686621 \\ https://hal.science/hal-00686621}

Submitted on 11 Apr 2012

HAL is a multi-disciplinary open access archive for the deposit and dissemination of scientific research documents, whether they are published or not. The documents may come from teaching and research institutions in France or abroad, or from public or private research centers.
L'archive ouverte pluridisciplinaire HAL, est destinée au dépôt et à la diffusion de documents scientifiques de niveau recherche, publiés ou non, émanant des établissements d'enseignement et de recherche français ou étrangers, des laboratoires publics ou privés. 


\title{
Combined model of human skin - Heat transfer in the vein and tissue: experimental and numerical study ${ }^{1}$
}

\author{
Domoina Ratovoson* — Vincent Huon* — Vincent Costalat** — \\ Franck Jourdan* \\ * Laboratoire de Mécanique et Génie Civil, \\ CC48, Université de Montpellier 2, Place Eugène Bataillon, \\ 34095 Montpellier, France \\ \{huon,jourdan,ratovoson\}@lmgc.univ-montp2.fr \\ ** Department of Neuroradiology, Gui de Chauliac Hospital \\ Université Montpellier 1 \\ France \\ v-costalat@,chu-montpellier.fr
}

\begin{abstract}
The aim of this study is to propose a combined model of heat transfer in the vein and tissue of human skin. It allows to better understand the thermomechanical behavior of the skin and its direct environment when exposed to strong thermal variations. The work is based on experimental and numerical investigations. The first experimental step consists in placing a cooled cylindrical steel bar on the skin of a human forearm and measuring the temperature change using an infrared camera. Blood circulation in the veins was seen to clearly influence heat diffusion. The second experimental step consists in measuring geometrical properties of the veins and blood velocity using an echo-Doppler probe. These experimental measurements provide a numerical model of the skin and its direct vicinity. The three-dimensional multilayer model uses Pennes equation to model biological tissue and the convective heat transport equation, to model blood. The properties of the biological materials obtained from the literature are validated by our experimentation. The numerical model is able to simulate the experimental observations, but also to estimate blood temperature and velocity in the veins.
\end{abstract}

KEY WORDS: Thermomechanics, Skin, Blood flow, Infrared imagery, Echo-Doppler, Numerical model

1 Received April 1, 2011; accepted for publication August 9, 2011. 


\section{Introduction}

The first works on thermal modeling of the skin date from the beginning of the $19^{\text {th }}$ century (Dupuytren, 1839), but quickly collided with the complexity of its structure. Skin is a multilayer, living material. Blood activity plays a dominant role in heat distribution. With current experimental techniques (Laser Doppler (De Boer et al., 1996) and (Bauera et al., 2006), infrared thermal imaging (Renkielska et al., 2006), (Boué et al., 2007), (Schnell et al., 2008) and (Bouzida et al., 2009)), observations have become more refined. The present study quantitatively highlights certain effects of blood circulation on heat diffusion. In the manner of studies undertaken by (Jakubowska et al., 2003), (Boué et al., 2007), (Schnell et al., 2008), and (Bouzida et al., 2009), an infrared camera was used to measure the change in temperature of the surface of the skin of a human forearm. Infrared thermography is a nondestructive technique giving highly accurate access to surface temperature. The originality of our study lies in its use of gravity effects to vary blood circulation. This approach allows us to quantify skin temperature variations due to a combination of velocity variation and blood temperature. An attempt is also made to develop a numerical model of skin, able to report observed phenomena and to be predictive. In this field, the model generally used is that of Pennes, proposed in 1948 (Pennes, 1948). The latter, often criticized for its oversimplified nature, was enriched by Wulff (Wulff, 1974) and Klinger (Klinger, 1974), then re-examined by Chen and Holmes (Chen et al., 1980). Their model highlights the failure of the Pennes model to take account the directional nature of blood flow or to incorporate the convective aspect of heat transfer by blood flow. Chen and Holmes developed a model of the heating effects of the various blood vessels according to architecture, geometry and blood flow characteristics. This model is more representative of reality than that of Pennes but it contains terms that appear inaccessible. Recently, new works have enriched the models of perfused tissues. One can quote the work of Raaymakers et al. (Raaymakers et al., 2009) on Discrete Vasculature Models (DIVA) or work developed in (Baish et al., 2009) combining Directed Perfusion Models and Effective Conductivity Models. Another interesting study by Khanafer and Vafai (Khanafer et al., 2009) proposes the use of porous media theory to model bioheat transport.

The Pennes model was chosen for the present study, assuming that thermoregulatory responses, during short time exposure to temperature variations, mainly depend on temperature and flow conditions in the veins. The same choice was made in the recent works of (Xu et al., 2008) and (Shih et al., 2007). The modeling of blood circulation and the diffusion of heat around the veins is what distinguishes our work from that of others. In this article, two types of experiments are carried out. The first, at the core of the study, concerns the use of infrared imagery. The results obtained with the infrared camera are analyzed and compared. The second experiment is the acquisition of certain mechanical and anatomical data of the subcutaneous veins, obtained by means of an echo-Doppler probe. All this data is used for the numerical model.

The thermomechanical multi-layer model is then developed with details of the method of resolution. The results of the numerical simulations are analyzed and the results of the experiment are compared with numerical calculations.

2. Experimental tests 
This section presents the two different experiments conducted for the needs of the study. The first experimental test consists in placing a cooled cylindrical steel bar on the skin of a human forearm and measuring the temperature change using an infrared camera. The second experimental test consists in measuring the geometrical properties of the veins and blood velocity using an Echography and Doppler acquisition.

2.1. Infrared thermal imaging

Infrared (IR) imagery, or thermography, is a method that allows the acquisition of infrared radiation related to the spatial distribution of heat on the examined objects. Our research team has been working for many years on the characterization of material. Infrared thermography is an experimental technique that we control relatively well, allowing us to accurately balance energy (Chrysochoos et al., 2010). The experimental setup included a focal plane array infrared camera (IRFPA Cedip Titanium). The wavelength of the camera is $3-5 \mathrm{~mm}$. The maximum frame-rate of the IR camera was 380 images per second, with each image consisting of $512 \times 640$ pixels. We used an IR measurement protocol based on an individual calibration of detector elements (Honorat et al, 2005), (Pron and Bissieux, 2005). This is an individual pixel calibration based on polynomial fitting of the temperature as a function of the signal $s_{\mathrm{i}}$ delivered by the $i^{\text {th }}$ element of the detector when the camera is placed in front of the black body source at different temperatures.

2.1.1. Experimental protocol

The aim of the experiment was to measure the temperature evolution in vivo of the skin of the forearm. A cylindrical steel bar was used, previously cooled in a deep freeze. The bar was placed on the forearm of a 28 year-old woman and the change in temperature was measured using the infrared camera. During measurements, the temperature of the experimentation room was maintained at $20^{\circ} \mathrm{C}$. The camera was placed at approximately $50 \mathrm{~cm}$ from the points of measurement. When the bar was placed on the skin, the measurements were restricted to a surface area of $(6 \times 10) \mathrm{cm}^{2}$. The circular cross-section of the cooled steel rod, with a radius of $1 \mathrm{~cm}$, was placed against the skin for 20 seconds and then removed. At the same moment the thermal camera started recording for a duration of 90 seconds. The forearm was immobilized to obtain exploitable results. Two forearm positions were studied: a horizontal position and a vertical position. Despite the use of insulating foam to hold the bar, the temperature of the bar could not be controlled while it was being placed on the forearm. Skin surface temperatures were measured at the same location for both positions. A circle drawn with a pencil identified the location of the cooled zone. The purpose was to quantify the effect of blood circulation on heat transfer. For the analysis, the parts containing veins were located and faster heating was expected in those zones. 

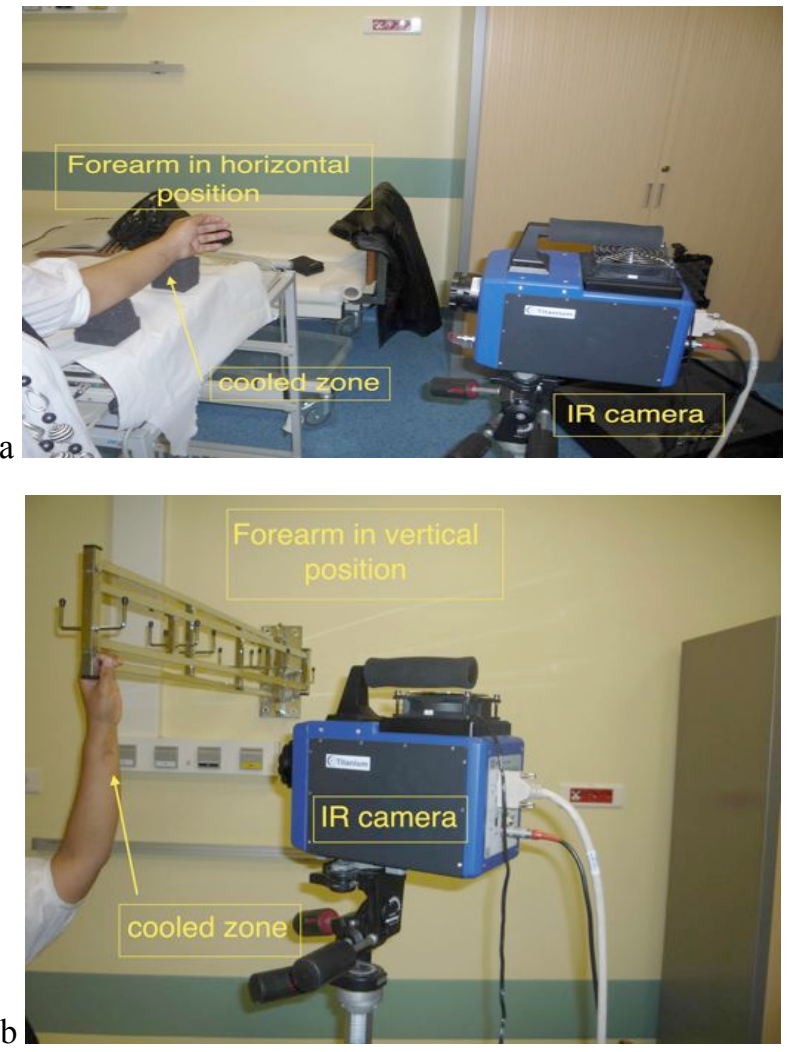

Figure 1. a) Forearm in the horizontal position; b) Forearm in vertical position. 2.1.2. Experimental results

2.1.2.1. Horizontal position

For the analysis, points were selected on the infrared image (see Figure 2). Certain points were located under the cylinder (3, 4 and 5) and others outside it (1, 2, 6 and 7). The infrared image, on the top of Figure 2, was taken $10 \mathrm{~s}$ after starting the recording. 

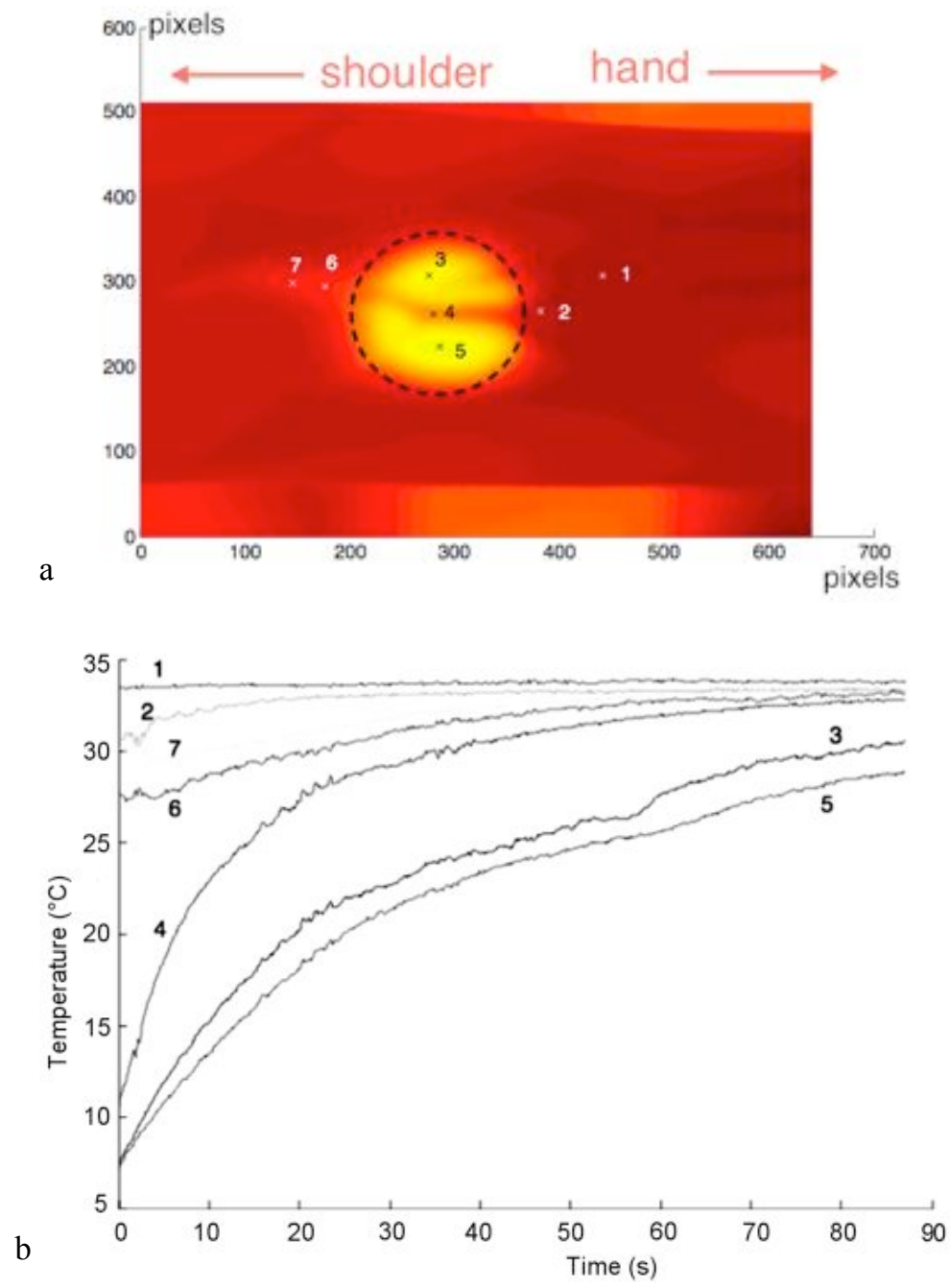

Figure 2. a) Localization of checkpoints. The dotted circle depicts the area covered by the cylinder. b) Temperature of checkpoints versus time (horizontal position).

Comments

Points 6 and 7 were located on the passage of a vein. Their temperature dropped and returned to thermal balance. This shows the influence of venous blood in heat diffusion. In the first moments the blood is cooled and lowers the temperature of downstream tissues.

Points 3 and 5 were located under the cooled zone with no vein passage. Their temperature increased until thermal balance.

Point 4 was under the cooled zone and on the passage of a vein. Its curve was shaped like those of points 3 and 5 but with a higher initial temperature.

Point 1 was outside the cylinder. There was little temperature variation. 
Point 2 was at the periphery of the cylinder and on the passage of a vein. Its temperature varied like those of points 6 and 7, but heating was faster.

2.1.2.2. Vertical position

The time interval between horizontal and vertical tests was about 15 minutes. An infrared image was taken before the cooling procedure to check that thermal balance had been recovered. Using the same experimental steps with the same bar, although not as cold $\left(-12^{\circ} \mathrm{C}\right)$ as in the horizontal position $\left(-17.7^{\circ} \mathrm{C}\right)$, we obtained the measurements presented in Figure 3. The checkpoints were the same as for the horizontal position. The infrared image, on the top of Figure 3, was taken 10 seconds after starting the recording.

Comments

The comments are exactly the same as for the horizontal position. Let us note however that the initial temperature imposed by the bar was higher $\left(-12^{\circ} \mathrm{C}\right)$ than for the horizontal position. In this experimentation, no attempt was made to control the initial temperature. Despite the use of insulating foam to hold the bar, the temperature of the bar could not be controlled while it was being placed on the forearm. Moreover, contact pressure was not controlled and contact resistance between solids largely depends on contact pressure. This is why we did not try to measure the heat transfer between the bar and the skin. We attempted instead to identify this boundary condition by reverse numerical analysis (see the numerical section). The vertical position led to a slower rate of temperature increase when compared to the horizontal position for locations above the vein. This difference may be accounted for by the fact that perfusion and blood circulation were less important in the vertical position than in the horizontal position. To show this more accurately, the following paragraph makes a comparative study between the horizontal and vertical positions.

2.1.3. Comparison of experimental results: (horizontal position and vertical position) In order to compare heating rate, the temperature measurements relating to the vertical and horizontal positions were recorded at the same checkpoints. Figure 4 is a superposition of Figures 2 and 3. The red curves are those of the vertical position and the dashed blue curves are those of the horizontal position.

Looking at Figure 4, it is difficult to say that the vertical position led to a slower rate of temperature increase for locations above the vein. Due to a higher temperature in the vertical position, the temperature gradient is smaller than in the horizontal position. However, a calculation for point 4 shows the difference of initial temperature rate between vertical and horizontal position as $16 \%$ smaller than it should be, according to the difference of initial temperature. 

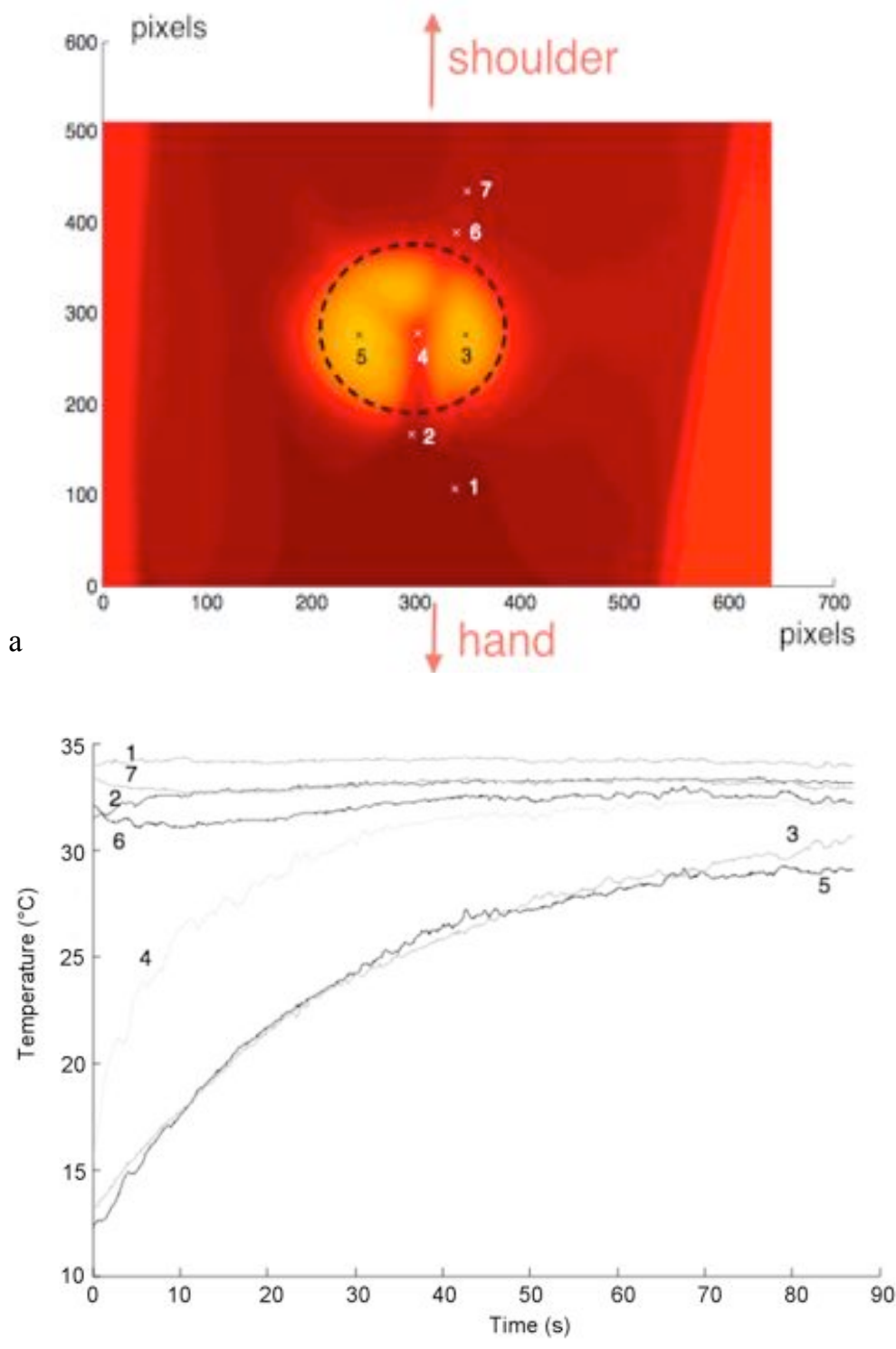

Figure 3. a) Localization of checkpoints. The dotted circle depicts the area covered by the cylinder. b) Temperature of checkpoints versus time (vertical position).

These experimental results quantitatively demonstrate, the effect of blood circulation on the thermal behavior of skin. The results were used to develop a predictive numerical model. 


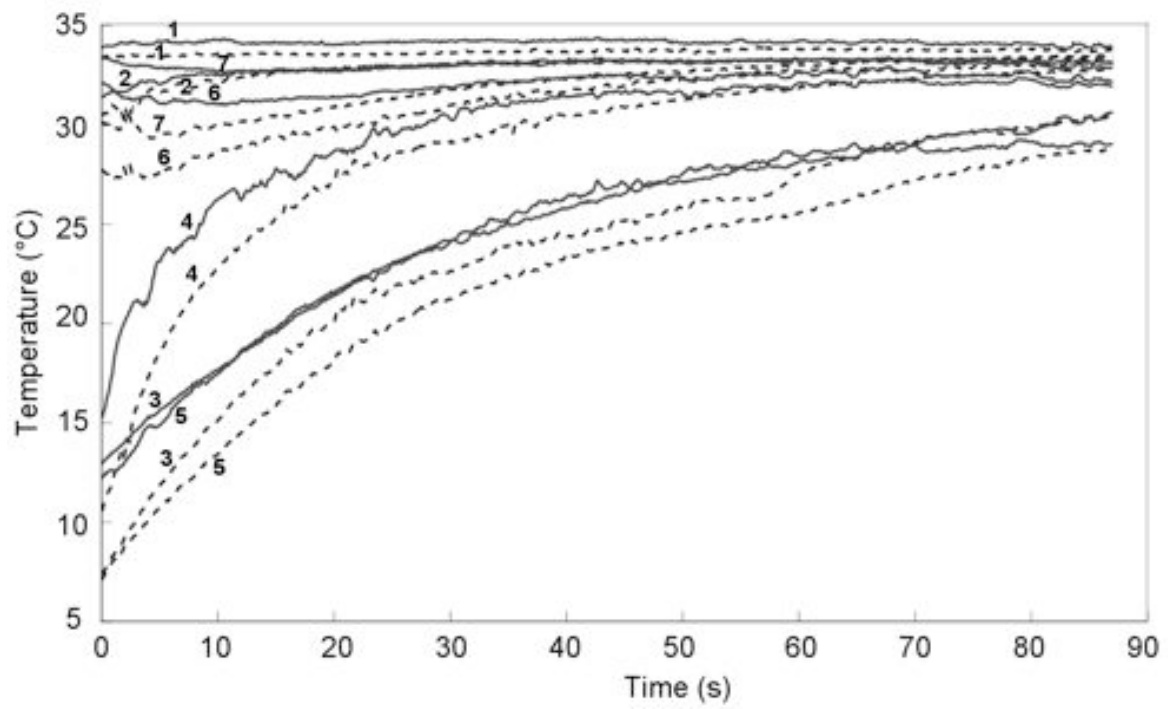

Figure 4. Comparison between horizontal (solid curves) and vertical (dashed curves) positions.

2.2. Echography and Doppler measurements

In order to obtain missing mechanical and anatomical information of the vein observed in the previous experimental results, blood velocity and geometrical properties, we used an Echo-Doppler probe SIEMENS, Sonoline Antares, 7,5 MHz. A gel was placed between the probe and the surface of the skin. The depth of gel interface was about $5 \mathrm{~mm}$ to avoid contact pressure during measurement. Blood velocity was recorded in the horizontal position, as in the previous section, then in the vertical position.

Figure 5 gives the blood velocity signal in the vein for the horizontal position. The mean value (an average over the sequence on the specific interval of time) is of about $2.3 \mathrm{~cm} / \mathrm{s}$.

Figure 6 gives the blood velocity signal in the vein for the vertical position. The mean value is of about $1.7 \mathrm{~cm} / \mathrm{s}$. One can observe a decrease of mean velocity between the vertical position and the horizontal position.

Figure 7 gives the depth and the diameter of the vein for the horizontal position. The depth is equal to $1.8 \mathrm{~mm}$ and the diameter is equal to $1.3 \mathrm{~mm}$.

The numerical model developed in the following section will use all these data. 


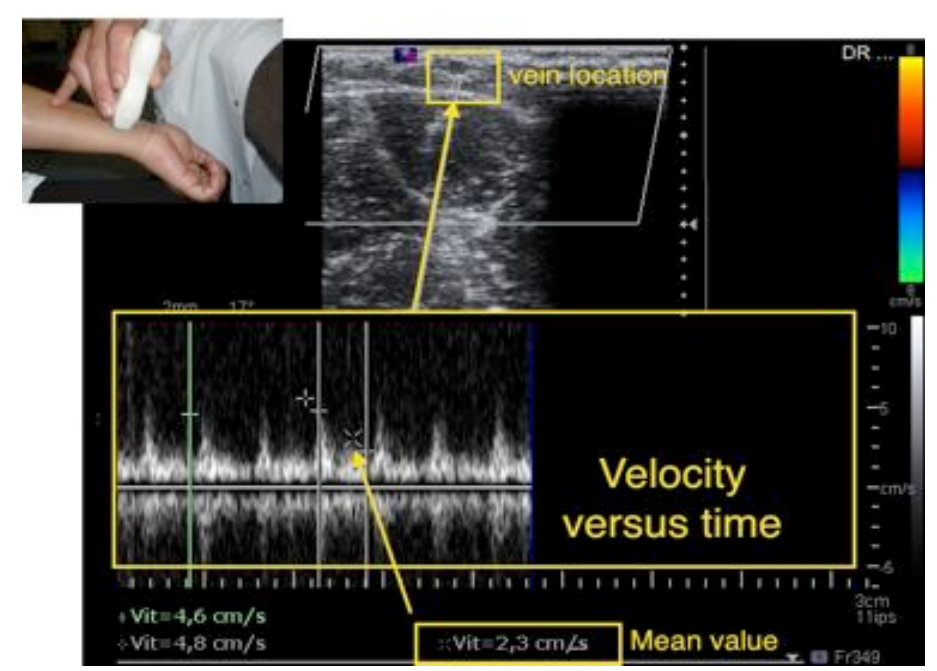

Figure 5. Blood velocity signal in the vein for the horizontal position.

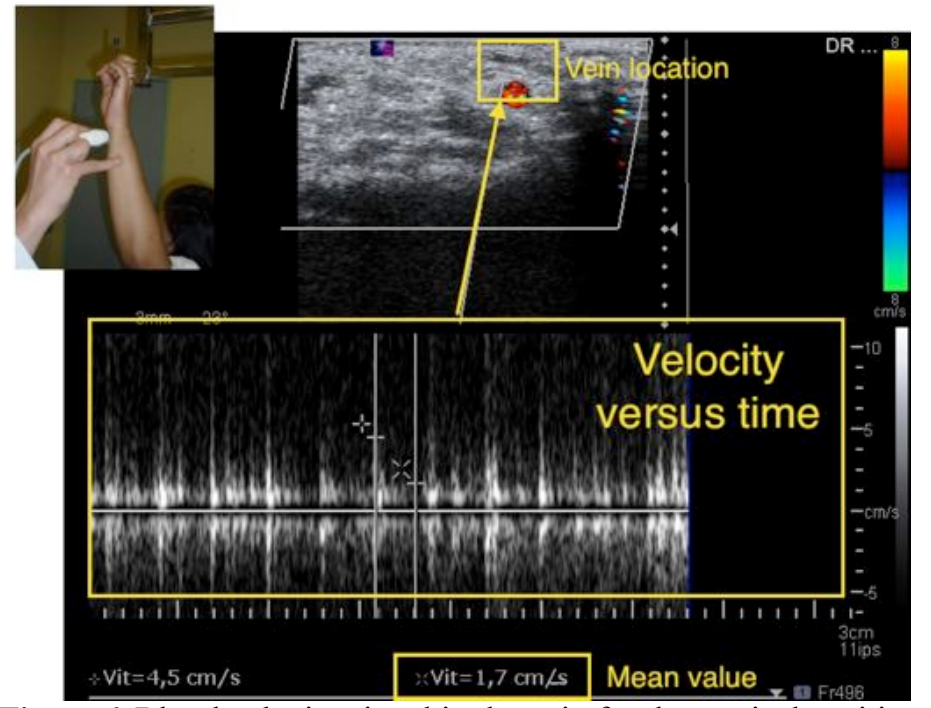

Figure 6. Blood velocity signal in the vein for the vertical position. 

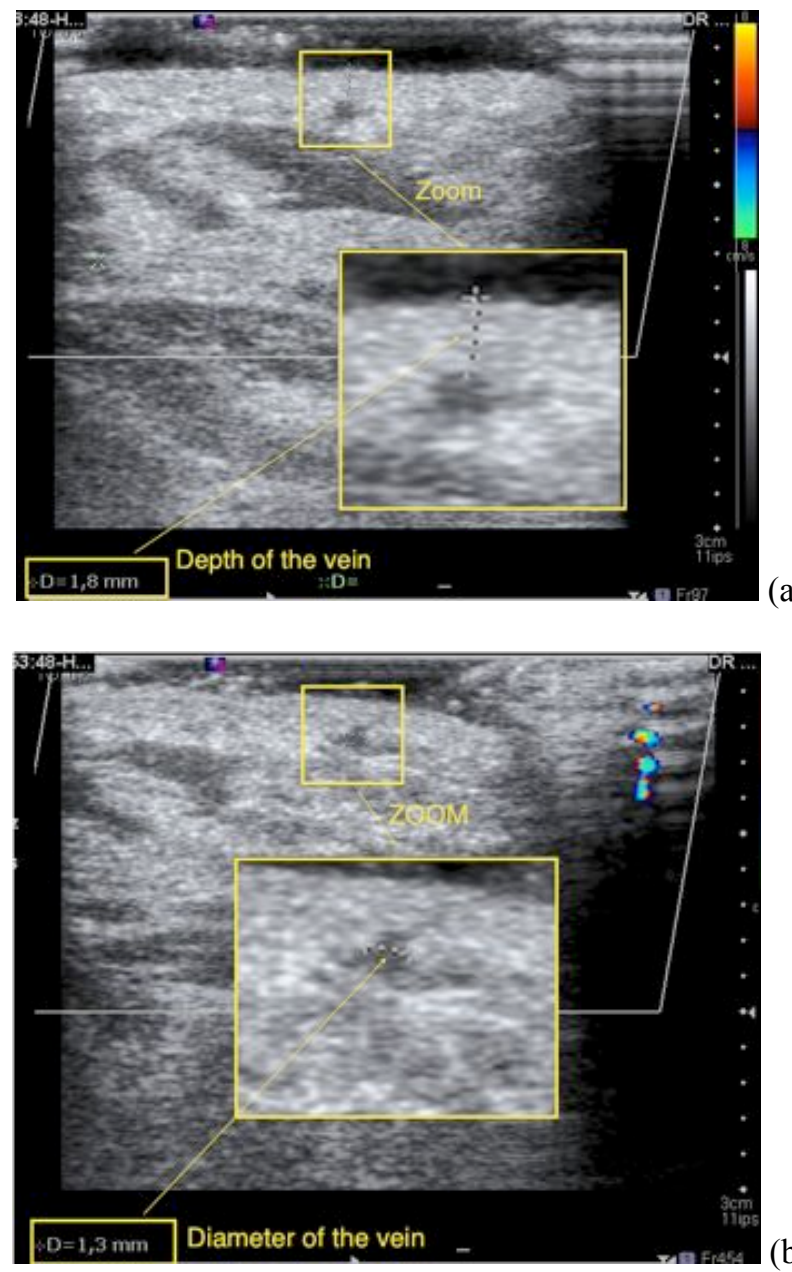

3. Modeling

Figure 7. Depth (a) and diameter (b) of the vein.

The model proposed in this paper, is a three-dimensional multi-layer model in which the veins are considered as fluid continuous media. The epidermis, the dermis and the hypodermis are considered as solid continuous media in which the evolution of heat is controlled by the Pennes equation. Only two layers (dermis and hypodermis) were taken into account (see Figure 8). The epidermis was neglected because of its small thickness. Between the dermis and the hypodermis, blood circulation was created with a material having transport velocity. A model of $10 \times 4 \mathrm{~cm}^{2}$ of surface and $4 \mathrm{~mm}$ of thickness was used. 


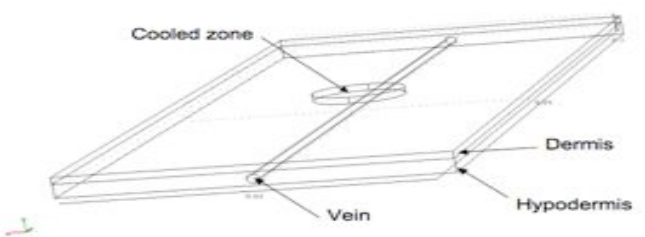

Figure 8. 3D model of skin.

3.1. Heat transfer in a fluid continuous medium

To model blood, the equations governing heat transfer in a fluid continuous medium are presented. The velocity vector of a particle $P$ of position $(x, y, z)$ at time $t$ is noted $\underline{U}=\left(u_{x}, u_{y}, u_{z}\right)$. Single underline is used for vector notation. Double underline is used for tensorial notation. Exponent " $t$ " denotes the transpose operator. The strain rate tensor is defined by:

$$
\underline{\underline{\varepsilon}}=\frac{1}{2}(\underline{\underline{\nabla u}}+\underline{\underline{\nabla u}}) \text {. }
$$

The temperature is noted as $T$. Heat transfer in a homogeneous, incompressible and viscous fluid is controlled by the following partial derivative equation:

$$
\rho C \frac{\partial T}{\partial t}-k \Delta T+\rho C \underline{U} \cdot \underline{\nabla} T=\mu\left(2 \underline{\underline{\varepsilon}}-\frac{2}{3} \underline{\nabla} \cdot \underline{u \underline{I}}\right): \underline{\underline{\nabla u}}+r
$$

where $r$ is the specific mass $\left(\mathrm{kg} \cdot \mathrm{m}^{-3}\right), C$ the specific heat $\left(\mathrm{J} \mathrm{kg}^{-1} \cdot \mathrm{K}^{-1}\right), k$ the thermal conductivity $\left(\mathrm{W} \cdot \mathrm{m}^{-1} \cdot \mathrm{K}^{-1}\right), m$ the viscosity $(\mathrm{Pa} . \mathrm{s}), r$ the heat source $\left(\mathrm{W} \cdot \mathrm{m}^{-3}\right)$, (neglected in our study). Tensor is the identity operator and ":" denotes the double contracted product. Note that the first term of the second member of equation [1] comes from the viscous dissipation.

The vein is supposed to be cylindrical. The position of the cylinder is determined by the coordinates of the center of its axis $x_{c}$ and $y_{c}$. The blood flow is assumed to be stationary. The velocity of the blood is then a parabolic function of direction $\vec{z}$ :

$$
u_{z}(x, y, z)=-\frac{U_{\max }}{R^{2}}\left[\left(x-x_{c}\right)^{2}+\left(y-y_{c}\right)^{2}\right]+U_{\max }
$$

where $U_{\max }$ is the maximum of velocity in the section of the vein and $R$ is the radius of the vein.

3.2. Pennes equation

For years, the Pennes model was criticized by some and defended by others. Despite these controversies and criticisms, most mathematical analyses carried out in biothermal transfers continue to be based on this equation (Klinger, 1974), (Weinbaum et al., 1984), (Shih et al., 2007) and (Xu et al., 2008). To model the biological tissues 
constituting the skin, the Pennes model was chosen. The first biothermal equation was developed by Pennes in 1948 (Pennes, 1948). There are two mechanisms characterizing heat transfer in living bodies: blood flow and metabolism. Before any study, and due to the varying size of the blood system, it is necessary to determine the scale to consider in studying heat transfers. The Pennes model proves to be most effective, with a scale ranging from a millimeter to several centimeters (Weinbaum et al., 1985). Pennes made the assumption that in a given volume of study, heat transfer $q_{p}$ between the blood and the tissue is proportional to the temperature difference between the arterial blood temperature $T_{a}$ (entering the volume of study) and the (outgoing) venous blood temperature $T_{v}$. The proportionality factor $w$ is called rate of perfusion.

$$
q_{p}=w(\rho C)_{b}\left(T_{a}-T_{v}\right)
$$

The index $\mathrm{b}$ is reserved for blood coefficient of materials. To connect the temperature of venous blood $T_{v}$ to the temperatures of arterial blood $T_{a}$ and of tissue $T$, Pennes introduced a coefficient $k^{\prime}$.

$$
T_{v}=T+k^{\prime}\left(T_{a}-T\right) \text {, }
$$

For $k^{\prime}=0$, thermal balancing is complete, blood leaves tissue at the temperature $T$. For $\mathrm{k}^{\prime}=1$, there is no temperature variation of blood passing in the volume of study (blood leaves tissue at the arterial temperature).

The metabolism is also included in the biothermal equation as a distribution of energy source:

$$
Q_{m e t}=Q_{m e t}^{o} Q_{10}^{\frac{T_{o}-T}{10}}
$$

where $Q_{m e t}^{o}$ is the basal metabolism at $37^{\circ} \mathrm{C}, Q_{10}$ is the coefficient of temperature dependence ranging between 2 and 3 and $T_{o}$ is chosen at $37^{\circ} \mathrm{C}$.

The general biothermal equation obtained with the balance of energy for a volume of tissue taking account of the blood perfusion and the metabolism is given by:

$$
\rho C \frac{\partial T}{\partial t}-\underline{\nabla} k_{t} \cdot \underline{\nabla} T=w \rho_{b} C_{b}\left(T_{a}-T_{v}\right)+Q_{m e t}
$$

where $\rho C \frac{\partial T}{\partial t}$ is the stored energy $\left(\mathrm{W} \cdot \mathrm{m}^{-3}\right), \underline{\nabla} k_{t} \cdot \underline{\nabla} T$ the heat transfer by conduction $\left(\mathrm{W} \cdot \mathrm{m}^{-3}\right), k_{t}$ the thermal conduction of the tissue, $w(\rho C)_{b}\left(T_{a}-T_{v}\right)$ the heat transfer by perfusion $\left(\mathrm{W} \cdot \mathrm{m}^{-3}\right)$ and $Q_{\text {met }}$ the heat generation of the metabolic internal power (W.m $\mathrm{m}^{-3}$ ).

To simplify the problem, the following assumptions were made:

- $k_{t}$ was chosen constant, thus

- $k^{\prime}$ was chosen to be null, so as $T_{v}=T$;

- The generation of metabolic internal power $Q_{\text {met }}$ was taken as constant.

$$
u_{z}(x, y, z)=-\frac{U_{\max }}{R^{2}}\left[\left(x-x_{c}\right)^{2}+\left(y-y_{c}\right)^{2}\right]+U_{\max },
$$




\subsection{Initial and boundary conditions}

In order to ensure a stationary distribution of temperature in the tissues, before the cooling process, an initialization step was included, of sufficient duration (200 s). Calculations were then carried out in two steps.

- Step 1 (duration $20 \mathrm{~s}$ ): A temperature $T_{a}$ was imposed on the lower part of the hypodermis, on the lateral walls and at the entrance of the vein (scheme (a) of Figure 9). On the front and back surfaces heat flux was null (scheme (b) of Figure 9). On a disc of $1 \mathrm{~cm}$ of radius of the upper part of the dermis (scheme (d) of Figure 9), the temperature was decreased to $T_{\min }$ in order to model the action of the bar. The rest of the upper part of the dermis was under a condition of convection (scheme (c) of Figure 9). Convection was modeled by Newton's law of cooling:

$$
k \frac{\partial T}{\partial n}=h\left(T-T_{e}\right)
$$

where $n$ is the normal vector at the surface, $h$ the coefficient of convection and $T_{e}$ the temperature of air. We chose $h=7 \mathrm{~W} \cdot \mathrm{m}^{-2} \cdot \mathrm{K}^{-1}$ (see Xu et al., 2008) and $T_{e}=20^{\circ} \mathrm{C}$. The connection between the layers was ensured by the continuity of the heat flow.
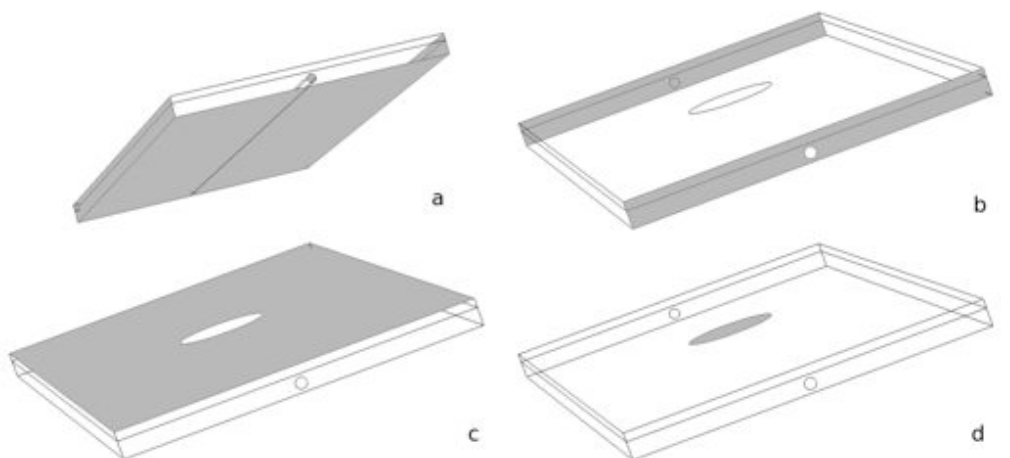

Figure 9. Boundary zones: (a) $\mathrm{T}=\mathrm{T}_{\mathrm{a}}$, (b) null heat flux, (c) convection with air, (d) $\mathrm{T}$ is decreased to $T_{\text {min }}$.

- Step 2 (duration $90 \mathrm{~s}$ ): The same boundary conditions were imposed as in step 1, but the action of the bar was replaced by a condition of convection with air. Thus, all the upper part of the dermis was under convection condition.

\section{Numerical simulations}

For the numerical resolution of heat equations [1] and [3], the finite element method was chosen and an implicit time integration scheme was adopted. The mesh contains 13.593 quadratic tetrahedral elements (see Figure 10).

This algorithm was programmed using COMSOL software. Calculations were carried out with a time step of $0.25 \mathrm{~s}$. The generations of metabolic internal power in the dermis and the hypodermis were fixed at $368 \mathrm{~W} \cdot \mathrm{m}^{-3}$ (see Roetzel et al., 1998). Vein diameter was equal to $1.3 \mathrm{~mm}$. The properties of materials are coming from (Gowrishankar et al., 2004) and collected in table 1. Blood viscosity was chosen equal to $2.510^{-2} \mathrm{~Pa} . \mathrm{s}^{-1}$. 


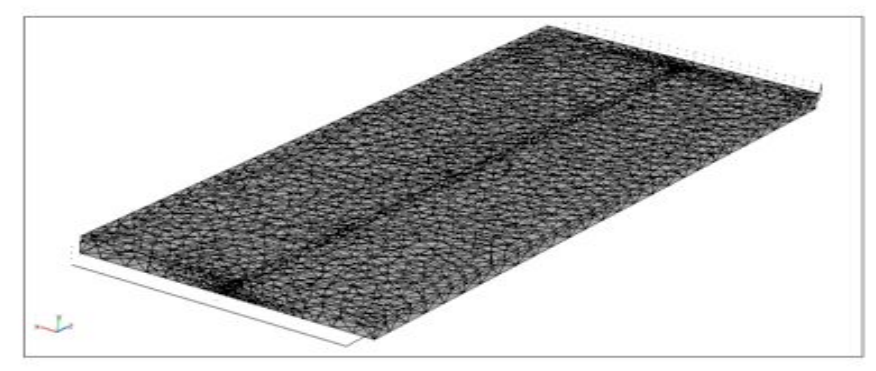

Figure 10. Finite element mesh: 13.593 quadratic tetrahedral elements.

\begin{tabular}{|c|c|c|c|c|c|c|}
\hline $\begin{array}{c}\text { Sub-domain } \\
\text { number }\end{array}$ & Layer & \begin{tabular}{|c|} 
Thickness \\
(m)
\end{tabular} & $\begin{array}{c}\text { Specific } \\
\text { heat } \\
C\left(\mathrm{~J} . \mathrm{kg}^{-1} \cdot{ }^{\circ} \mathrm{C}^{-1}\right)\end{array}$ & $\begin{array}{c}\text { Thermal } \\
\text { conductivity } \\
k\left(\mathrm{~W} \cdot \mathrm{m}^{-1} \cdot{ }^{o} \mathrm{C}^{-1}\right)\end{array}$ & $\begin{array}{c}\text { Specific } \\
\text { mass } \\
\rho\left(\mathrm{kg} \cdot \mathrm{m}^{-3}\right)\end{array}$ & $\begin{array}{c}\text { Rate } \\
\text { of perfusion } \\
w\left(\mathrm{~s}^{-1}\right)\end{array}$ \\
\hline 0 & Epidermis & $0.0810^{-3}$ & 3590 & 0.24 & 1200 & 0 \\
\hline 1 & Dermis & 0.001 & 3300 & 0.45 & 1200 & 0.00125 \\
\hline 2 & Blood & $0.0013^{*}$ & 3770 & 0.45 & 1060 & 0 \\
\hline 3 & Hypodermis & 0.003 & 2500 & 0.19 & 1000 & 0.00125 \\
\hline
\end{tabular}

0.0013* is the thickness of the veins and can vary from 1 to $3 \mathrm{~mm}$.

Table 1. Material properties.

The first series of comparisons was carried out on the horizontal forearm position. This fixed the parameters of the model and in particular blood temperature and velocity. They were selected to best fit experimental data. The second series was carried out on the vertical position and validated the choice of parameters. It also allowed blood temperature and velocity variation to be estimated.

4.1. Numerical comparisons for horizontal position

In Figures 11, 12 and 13, the curves with symbols correspond to experimental measurements and continuous lines result from calculating the temperature of points having the same coordinates as checkpoints of Figure 2. Note that only steps 1 and 2 are represented in the Figures. The initialization step is hidden from view in all Figures of the article in order to obtain a better zoom of the useful results. Different vein depths ( $1 \mathrm{~mm}$ and $1.8 \mathrm{~mm})$ and blood flow velocities $\left(3.4 \mathrm{~cm} . \mathrm{s}^{-1}, 2.3 \mathrm{~cm} . \mathrm{s}^{-1}\right.$ and $\left.1.7 \mathrm{~cm} . \mathrm{s}^{-1}\right)$ were tested. The depth of $1.8 \mathrm{~mm}$ corresponds to the measured value. In this comparative study, we used blood temperature $T_{a}=35.5^{\circ} \mathrm{C}$.

Figure 11 gives a comparison between experimental and numerical results for the horizontal position with $U_{\max }=3.4 \mathrm{~cm} . \mathrm{s}^{-1}$ and a depth of the vein equal to $1.8 \mathrm{~mm}$. The numerical results are not satisfactory. Figure 12 gives a comparison between experimental and numerical results for the horizontal position with $U_{\max }=3.4 \mathrm{~cm} . \mathrm{s}^{-1}$ and a depth of the vein equal to $1 \mathrm{~mm}$. The results are better than for a depth of $1.8 \mathrm{~mm}$, 


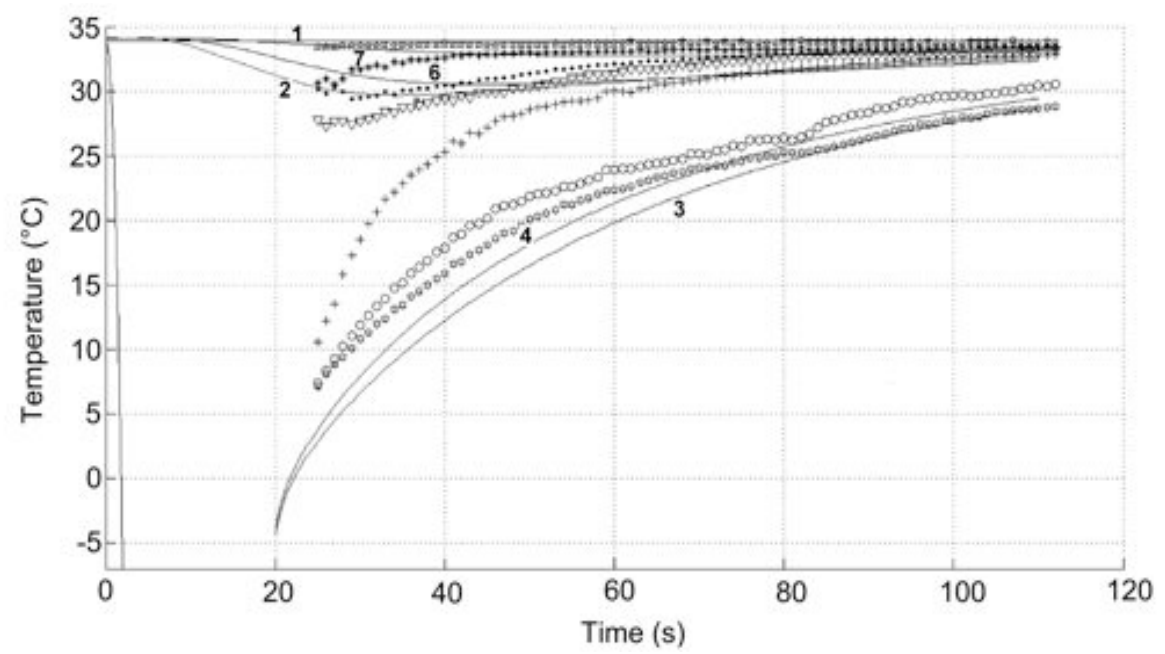

Figure 11. Comparison between experimental and numerical results for the horizontal position with $U_{\max }=3.4 \mathrm{~cm} \cdot \mathrm{s}^{-1}$ and a depth of vein of $1.8 \mathrm{~mm}$.

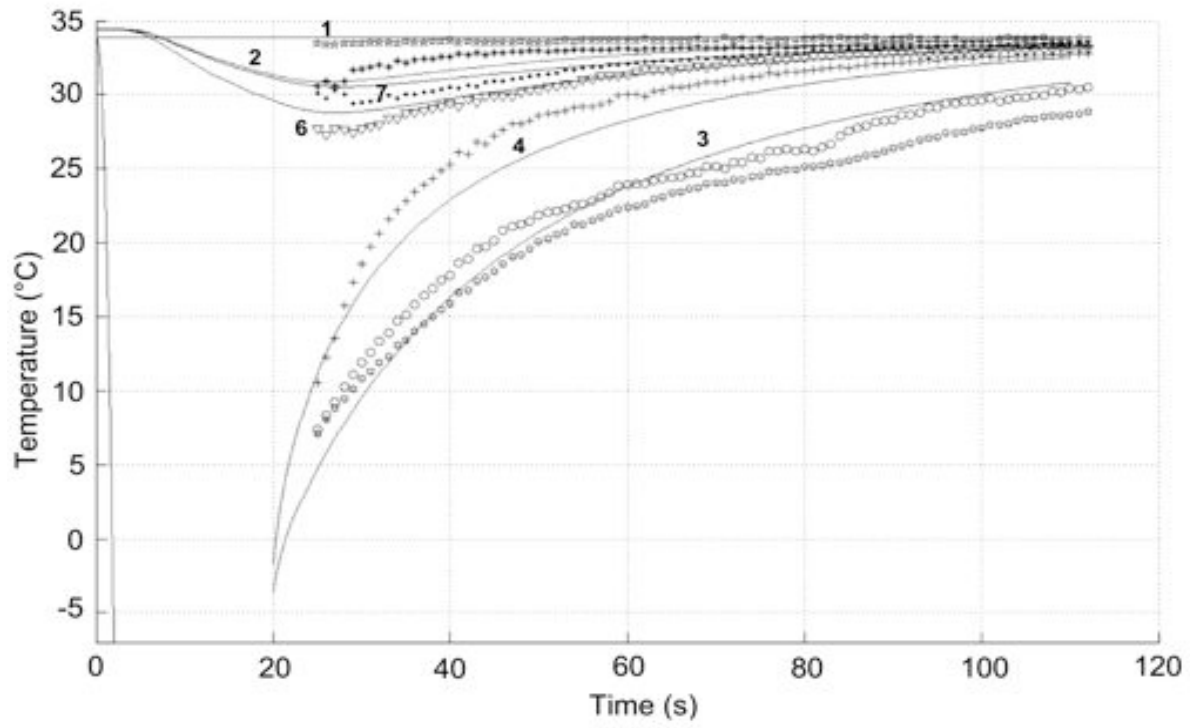

Figure 12. Comparison between experimental and numerical results for the horizontal position with $U_{\max }=3.4 \mathrm{~cm} \cdot \mathrm{s}^{-1}$ and a depth of vein of $1 \mathrm{~mm}$. 


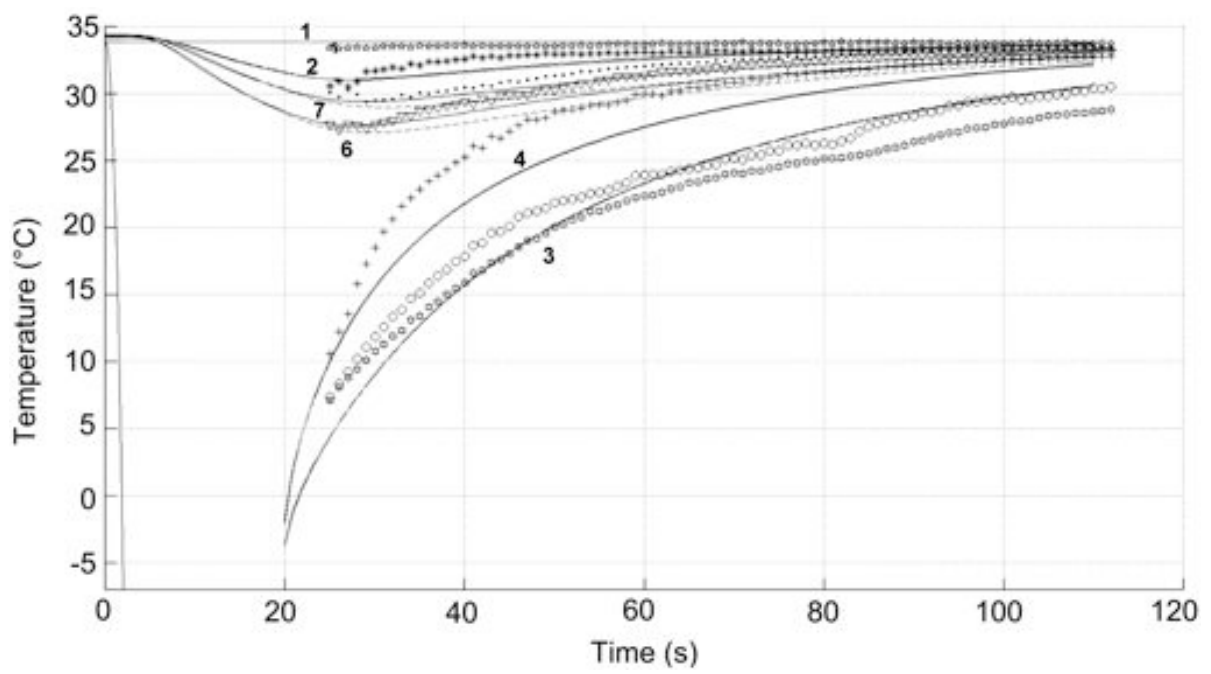

Figure 13. Comparison between experimental and numerical results for the horizontal position with a depth of vein $=1 \mathrm{~mm}$. The dashed red curves correspond to $U_{\max }=$ $1.7 \mathrm{~cm} . \mathrm{s}^{-1}$. The solid curves correspond to $U_{\max }=2.3 \mathrm{~cm} \cdot \mathrm{s}^{-1}$.

but the heating of points 6 and 7 is too important. Velocities $U_{\max }=2.3 \mathrm{~cm} . \mathrm{s}^{-1}$ and $U_{\max }$ $=1.7 \mathrm{~cm} . \mathrm{s}^{-1}$ were then tested. Figure 13 shows that the best fit is obtained for a velocity $U_{\max }=2.3 \mathrm{~cm} . \mathrm{s}^{-1}$.

4.2. Numerical comparisons for the vertical position

The checkpoints were roughly the same as for the horizontal position. The comparison of the results is presented in Figures 14 and 15. As in the horizontal position, different blood flow velocities $\left(2.5 \mathrm{~cm} / \mathrm{s}, 2.3 \mathrm{~cm} . \mathrm{s}^{-1}\right.$ and $\left.1.7 \mathrm{~cm} . \mathrm{s}^{-1}\right)$ were tested. In this comparative study, we used blood temperature $T_{a}=35^{\circ} \mathrm{C}$.

Figure 14 gives a comparison between experimental and numerical results for the vertical position with $U_{\max }=2.5 \mathrm{~cm} \cdot \mathrm{s}^{-1}$ and $U_{\max }=1.7 \mathrm{~cm} \cdot \mathrm{s}^{-1}$ with a depth of vein equal to $1 \mathrm{~mm}$. Heating is more important with $U_{\max }=2.5 \mathrm{~cm} \cdot \mathrm{s}^{-1}$, but the difference between these simulations is not significant. The influence of blood temperature $T_{a}$ is estimated in Figure 15. This Figure presents a comparison between experimental and numerical results. The blue curves are obtained using $U_{\max }=1.7 \mathrm{~cm} . \mathrm{s}^{-1}$ and a blood temperature $T_{a}=35^{\circ} \mathrm{C}$. The dashed red curves result from calculations using Umax $=2: 3 \mathrm{~cm} / \mathrm{s}$ and a blood temperature $T_{a}=35.5^{\circ} \mathrm{C}$. These latter parameters are those that best fit experimental result in the horizontal position. A zoom of the useful zone of Figure 16 shows that the initial temperature is higher when $T_{a}=35.5^{\circ} \mathrm{C}$ and heating is more important for points 2, 6 and 7 . 


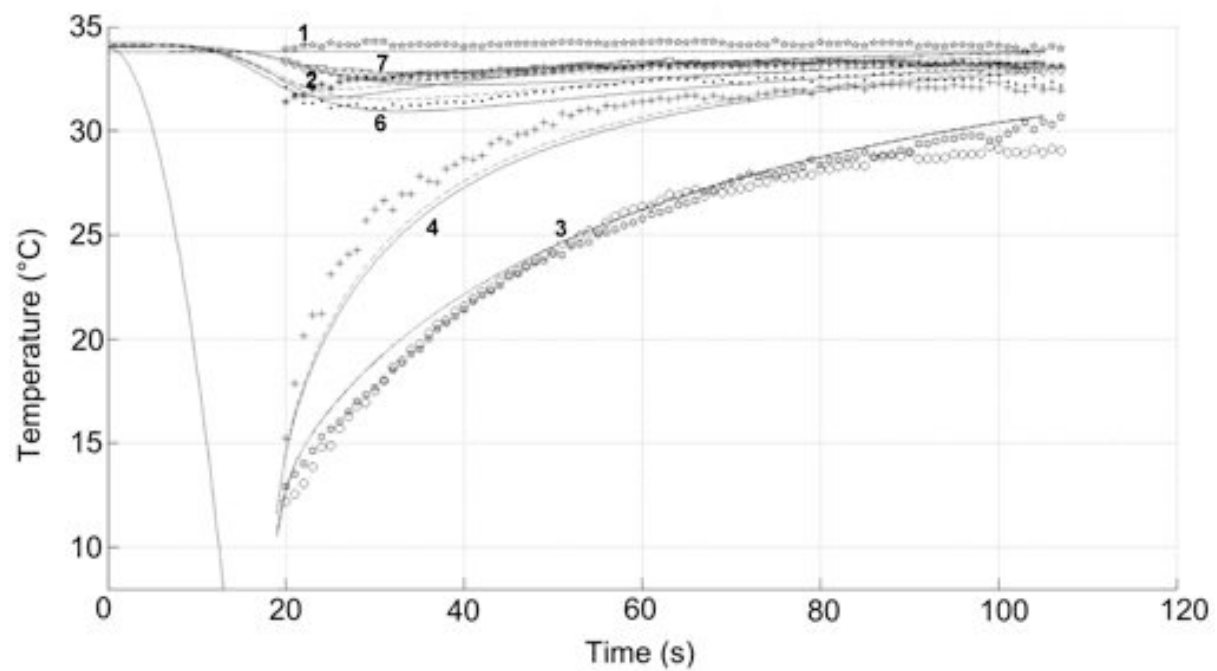

Figure 14. Comparison between experimental and numerical results for the vertical position with a depth of vein equal to $1 \mathrm{~mm}$. The solid curves correspond to $U_{\max }=$ $1.7 \mathrm{~cm} . \mathrm{s}^{-1}$. The dashed curves correspond to $\mathrm{U}_{\max }=2.5 \mathrm{~cm} \cdot \mathrm{s}^{-1}$.

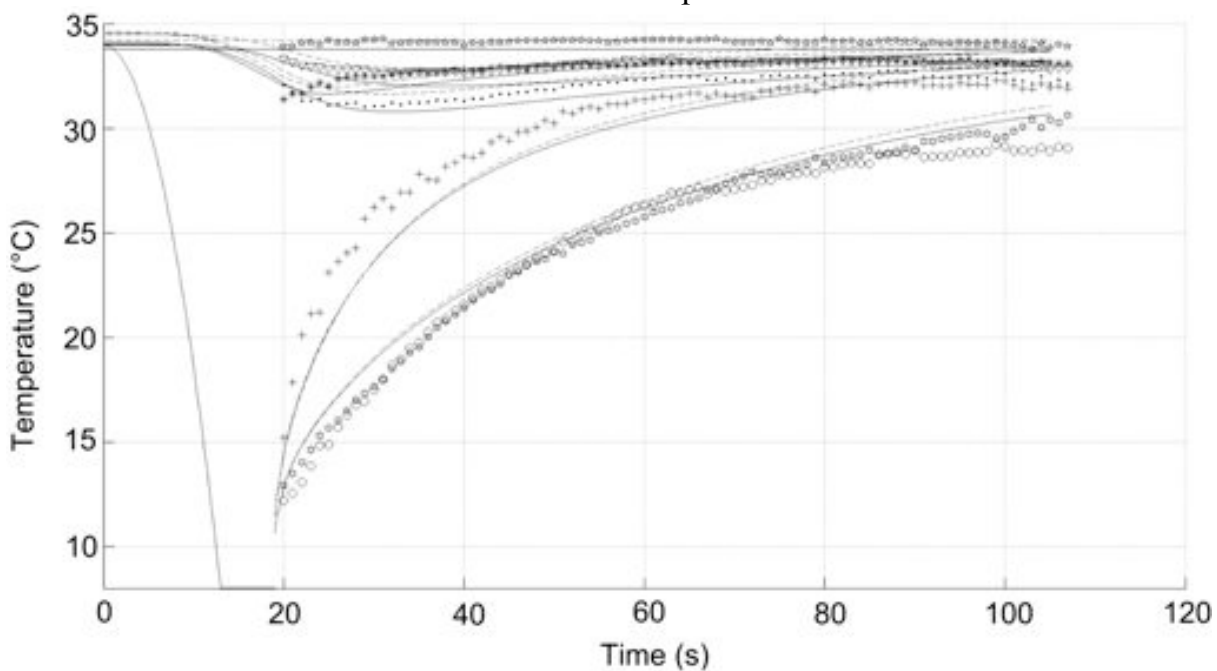

Figure 15. Comparison between experimental and numerical results for the vertical position with a depth of vein equal to $1 \mathrm{~mm}$. The solid curves correspond to $\mathrm{U}_{\max }=$ $1.7 \mathrm{~cm} \cdot \mathrm{s}^{-1}$ and a blood temperature $\mathrm{T}_{\mathrm{a}}=35^{\circ} \mathrm{C}$. The dashed curves correspond to $\mathrm{U}_{\max }=$ 2. $\mathrm{cm} \cdot \mathrm{s}^{-1}$ and a blood temperature $\mathrm{T}_{\mathrm{a}}=35.5^{\circ} \mathrm{C}$. 


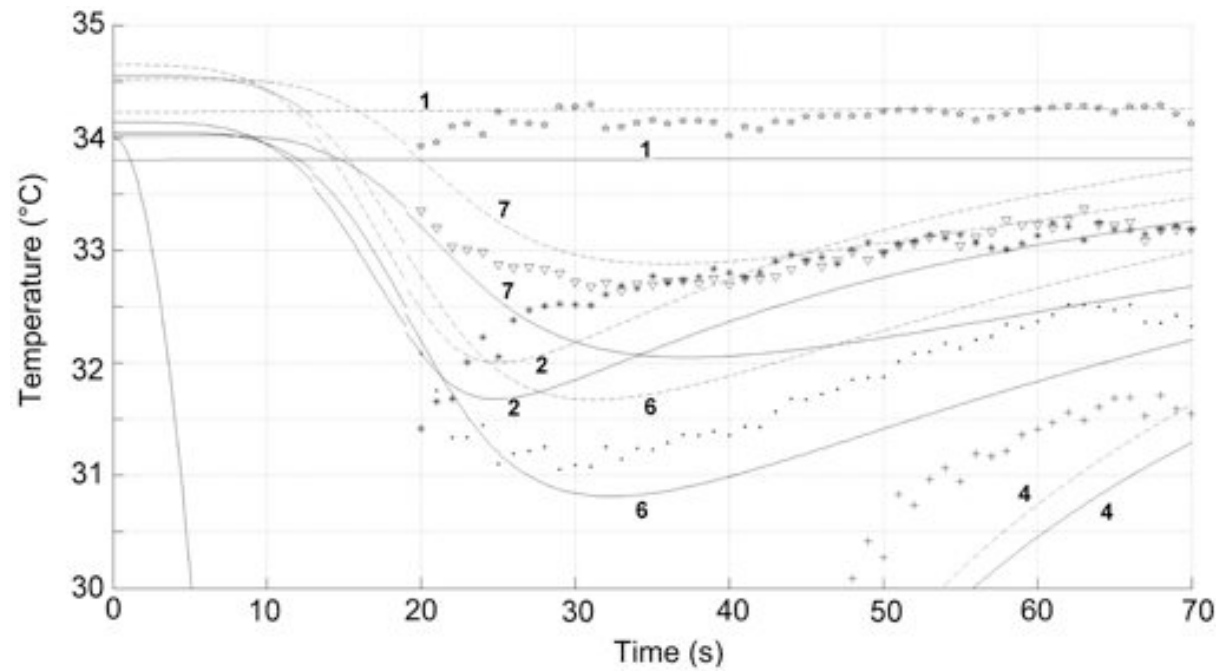

Figure 16. Zoom of Figure 15.

For the vertical position, the best fit is obtained for a depth of $1 \mathrm{~mm}$, a velocity $U_{\max }=$ $1.7 \mathrm{~cm} . \mathrm{s}^{-1}$ and a blood temperature $\mathrm{Ta}=35^{\circ} \mathrm{C}$. Figure 17 shows the thermal distribution in the model at the end of calculation.

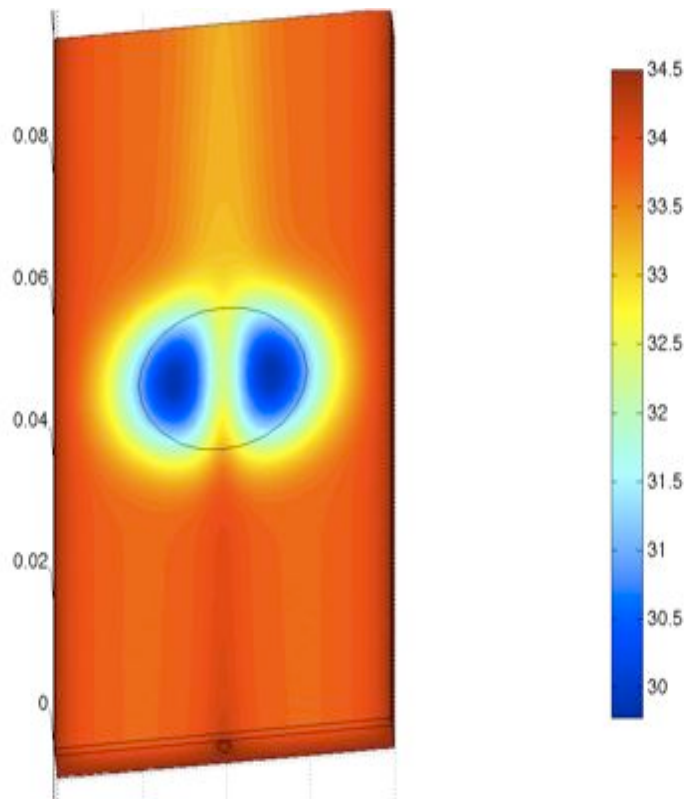

Figure 17. Thermal distribution (in ${ }^{\circ} \mathrm{C}$ ) at the end of calculation for vertical position.

4.3. Comments and discussions

- Being unaware of the real boundary conditions created by the bar, we adopted two different conditions. These boundary conditions were obtained by reverse analysis. 
Several decrease in temperature were tested. For the horizontal position, the selected decrease of temperature was fast and stabilized at $T_{\min }=-7^{\circ} \mathrm{C}$, whereas for the vertical position the decrease of temperature was slower and stabilized at $T_{\min }=8^{\circ} \mathrm{C}$. The heat stored in the cooled bar is less important at the beginning of the experiment in vertical position, which can explain the difference between imposed temperature $T_{\min }$.

- The numerical model reproduces experimental observations. It enables the properties of materials to be validated. It is able to simulate the heat transport carried out by the blood flow. This particular point is shown by a drop followed by a fast rise in the temperature of tissue downstream from the cooled zone. This phenomenon is observed both experimentally and numerically.

- Concerning blood temperature and velocity, we noted that to best fit the experimental curves, in the case of vertical position, it was necessary to decrease the temperature and the velocity of blood. This decrease of temperature could be the result of a reduction of the perfusion, i.e. a reduction in the quantity of blood in the small vessels. This reduction tends to cool the tissues and the blood circulating in the veins around the vessels.

- The depth of the vein was measured to $1.8 \mathrm{~mm}$ from the surface of the skin, whereas the best numerical results were obtained for a depth of $1 \mathrm{~mm}$. The difference could be explained by a reduction of the thickness of the dermis following the pressure exerted by the bar during step 1 . This pressure brings the vein closer to the bar. Moreover, vein depth is not constant throughout the length of the studied zone. A depth of $1 \mathrm{~mm}$ could be the average value. Finally, some measurement errors could also account for this difference.

- During 90 seconds (duration of the recording), the influence of metabolic power generation $Q_{m e t}$ and perfusion rate $W$ were not significant in the numerical results. For this reason no parametric study relative to $Q_{m e t}$ and $W$ was presented. Numerical observation confirms the works of (Shitzer et al., 1985), (Deng et al., 2000), (YongGang et al., 2007) which suggest that the effects of perfusion rate are significant in the case of long lasting thermal exposures and of low intensity or in the case of microwave exposure (Ozen et al., 2008).

5. Conclusion

A thermal camera was used to record the temperature change of the skin of a human forearm, cooled for 20 seconds. The measurements highlighted complex phenomena. Certain effects of blood circulation on temperature diffusion were quantitatively observed. The influence of blood circulation was highlighted by comparing the temperatures obtained for a horizontal position and for a vertical position of the studied forearm. It was noted that heating is less important in the vertical position than in horizontal position, which is justified by the effect of gravity on blood flow. Blood has more difficulty circulating in the vertical position than in the horizontal position. The experimental approach is perfectible. The cooling procedure needs to be improved in order to control boundary conditions. In parallel, a numerical multi-layer model was developed, based on Pennes equation and able to simulate blood flow in the veins. The model contains numerous parameters. A numerical test campaign was conducted. Some numerical comparisons were presented, such as the sensitivity to the depth of the vein and the blood flow. This model can be used to validate the thermomechanical properties of the living materials constituting the various layers. It 
also provided average values of blood velocity in the veins. An average velocity of about $2 \mathrm{~cm} . \mathrm{s}^{-1}$ was measured by Doppler and confirmed by simulation. This model confirms that the actions of blood perfusion and the metabolism are negligible for this kind of thermal stress. Coupling a nondestructive experimental approach with a numerical model provides insight into the thermomechanical behavior of living tissue, as well as representing a promising approach. It offers a tool to explore the behavior of tissue exposed to high temperatures. Experimentation at high temperature is not accessible in vivo in humans, which is why work will continue to be carried out by modeling. However to refine the model, a study will be conducted on the heating of the skin, the temperatures having to be controlled to avoid burns. The goal is to compare the differences in temperature change between cooling and heating. 6. References

Baish J.W., Mukundakrishnan K., Ayyaswamy P.S., "Numerical Models of Blood Flow Effects in Biological Tissues", Advances in Numerical Heat Transfer, W . J . Minkowycz, E . M . Sparrow, and J . P . Abraham CRC Press, Vol. 3, p. 29-74, 2009. Bauera D., Grebe R., Ehrlacher A., "A new method to model change in cutaneous blood flow due to mechanical skin irritation: Part II: Parameter identification procedure", Journal of Theoretical Biology, vol. Volume 238, Issue 3, 7, p. 588-596, 2006.

Boué C., Cassagne F., Massoud C., Fournier D., "Thermal imaging of a vein of the forearm: Analysis and thermal modelling", Infrared Physics \& Technology, vol. Volume 51, Issue 1, p. 13-20, 2007.

Bouzida N., Bendada A., Maldague X.P., "Visualization of body thermoregulation by infrared imaging", Journal of Thermal Biology, vol. 34, p. 120-126, 2009.

Chen M., Holmes K., "Microvascular Contributions in Tissue Heat Transfer", Annals of the New York Academy of Sciences, vol. Vol. 335, p. 137-150, 1980.

Chrysochoos A., Huon V., Jourdan F., Muracciole J.-M., Peyroux R., Wattrisse B., "Use of Full-Field Digital Image Correlation and Infrared Thermography Measurements for the Thermomechanical Analysis of Material Behaviour", Strain, vol. Volume 46, Issue 1, p. 117-130, 2010.

De Boer E., Bruynzeel D., "Patch tests : Evaluation by instrumental methods", Clinics in Dermatology, vol. 31, p. 203-222, 1996.

Deng Z.-S., Liu J., "Parametric studies on the phase shift method to measure the blood perfusion of biological bodies", Med. Eng. Phys., vol. 22, p. 693-702, 2000.

Dupuytren G., Leçons orales de clinique chirurgicale, Germer Bailliere, Paris, 1839. Gowrishankar T., Stewart D., Martin G., Weaver J., "Transport lattice models of heat transport in skin with spatially heterogeneous, temperature-dependent perfusion", BioMedical Engineering OnLine, vol. 3, p. 3-42, 2004.

Honorat V., Moreau S., Muracciole J.-M., Wattrisse B., Chrysochoos A., "Calorimetric analysis of polymer behaviour using a pixel calibration of an IRFPA camera", Int J. on Quantitative Infrared Thermography, V 2, 2: 153-172, 2005.

Jakubowska T., Wiecek B., Wysocki M., Peszynski-Drews C., "Thermal Signatures for Breast Cancer Screening Comparative Study", Proc. IEEE EMBS Conf. Cancun, Mexico, Sep 17-21, 2003. 
Khanafer K., Vafai K., "Synthesis of Mathematical Models Representing Bioheat Transport", Advance in Numerical Heat Transfer, W . J . Minkowycz, E . M . Sparrow, and J . P . Abraham CRC Press, vol. Vol. 3, p. 1-28, 2009.

Klinger H., "Heat transfer in perfused biological tissue. I. general theory", Bull. Math. Biol., vol. 21, p. 494-497, 1974.

Ozen S., Helhel S., Cerezci O., "Heat analysis of biological tissue exposed to microwave by using thermal wave model of bio-heat transfer (TWMBT)", Burns, vol. 34 (1), p. 45-49, 2008.

Pennes H.H., "Analysis of Tissue and Arterial Blood Temperatures in Resting Human Forearm”, Journal of Applied Physiology, vol. 1, p. 93-122, 1948.

Pron H., Bissieux C., "Focal plane array infrared cameras as research tools", Int J. on Quantitative Infrared Thermography, V 1, 2: 229-240, 2005.

Raaymakers B.W., Kotte A.N.T.J., Lagendijk J.J.W., "Discrete Vasculature (DIVA) Model Simulating the Thermal Impact of Individual Blood Vessels for In Vivo Heat Transfer", Advance in Numerical Heat Transfer, W.J. Minkowycz, E.M. Sparrow, and J.P. Abraham CRC Press, vol. Vol. 3, p. 121-147, 2009.

Renkielska A., Nowakowski A., Kaczmarek M., Ruminski J., "Burn depths evaluation based on active dynamic IR thermal imaging - A preliminary study", Burns, vol. 32, p. 867-875, 2006.

Roetzel W., Xuan Y., "Transient response of the human limb to an external stimulusTransient response of the human limb to an external stimulus", Int. J. Heat Mass Transfer, vol. 41, p. 229-239, 1998.

Schnell H., Zaspel J., "Cooling extensive burns: Sprayed coolants can improve initial cooling management: A thermography-based study", Burns, vol. Volume 34, Issue 4, p. 505-508, 2008.

Shih T., Yuan P., Lin W., Kou H., "Analytical analysis of the Pennes bioheat transfer equation with sinusoidal heat flux condition on skin surface", Medical Engineering and Physics, vol. 29, p. 946-953, 2007.

Shitzer A., Eberhart R. C., Heat transfer in medicine and biology: Analysis and application, vol 1 and 2., Plenum Press, New York, 1985.

Weinbaum S., Jiji L., "A new simplified bioheat equation for the effect of blood flow on local average tissue temperature", ASME Trans. J. Biomech. Eng., vol. 107, p. 131$141,1985$.

Weinbaum S., Jiji L., Lemos D., "Theory and Experiment for the Effect of Vascular Temperature on Surface Tissue Heat Transfer - Part I: Anatomical Foundation and Model Conceptualization", ASME Journal of Biomedical Engineering, vol. 106, p. 321-330, 1984.

Wulff W., "The energy conservation equation for living tissue", IEEE Transactions on Biomedical Engineering, vol. 36, p. 403-415, 1974.

Xu F., Lu T., Seffen K.A., "Biothermomechanics of skin tissue", Journal of the Mechanics and Physics of Solids, vol. 56 (5), p. 1852-1884, 2008.

Yong-Gang L., Jing L., "Measurement of local tissue perfusion through a minimally invasive heating bead", Heat and Mass Transfer, vol. 44, Issue 2, p. 201-211, 2007. 